\title{
FACTORS CONSTRAINING THE APPLICATION OF LESSONS LEARNED ON CONSTRUCTION PROJECTS IN NIGERIA
}

\author{
Benedict Amade, Precious Keinpirima Iringe-Koko \\ Department of Project Management Technology, Federal University of Technology, \\ Owerri, Nigeria
}

\begin{abstract}
Lessons learned is a new form of creating knowledge while also sharing information amongst practitioners in the built environment. The aim of this study was to identify and evaluate the factors constraining lessons learned application in the delivery of construction projects in Port-Harcourt, Rivers State, Nigeria. The study adopted a survey research design technique with the aid of a snow balling sampling technique. A sample size of 111 respondents was determined from a population of 200 made up of practitioners from the built industry. These samples were drawn from some construction firms located in the study area. The questionnaire for the survey was modeled using the Likert scale. Retrieved data were later presented via charts and figures, while Cronbach's alpha coefficient tests and factor analysis were deployed in analyzing the main issues underlying the study via the IBM SPSS Statistics version 20. The findings from the study show that the constraints to lessons learned deployment could be grouped into six (6) constraints; the most important factor grouping being lack of comprehensive approach to lessons learned followed by lack of time, degeneration into blame sessions that becomes emotionally damaging, poor organizational culture, lack of willingness to share project faults caused by individual or group performance and finally lack of a lessons learned repository.
\end{abstract}

Key words: Constraints to lessons learned, construction project delivery, lessons learned.

\section{INTRODUCTION}

One of the significant challenges confronting public and business project organizations is the ability to ensure that lessons are learned and previous mistakes identified during the life of a project are not repeated. The knowledge and project management literature abounds with suggestions that lessons learned in practice are seldom corrected (Duffield, \& Whitty, 2012). While Ekambaram and Økland (2019) were of the view that although the gains of knowledge transfer are still visible, hence, it is still difficult implementing inter-project knowledge transfer and harvest the desired benefits ensuing there from. The construction industry according to Che Munaaim, Abdul-Rahman, Low and Yahya (2007), is notoriously known for its time-bound, one-shot, complex, fragmented, unique, and goal driven nature. In this era of knowledge and technology, construction projects have increasingly become complex and fragmented in size, construction methods, designs, human relationships, and clients' needs. Adequate information and knowledge is needed to drive a project throughout it's shelve life. Hence, each project requires enough contribution and integration of knowledge from the various multidisciplinary team members alongside their knowledge and experiences from previous projects to bring to bear.

According to Chin, Gao and Low (2015), the construction industry has been limited, largely due to the temporary state of most projects and their associated impediments. The dearth of research in this specialized area often gives rise to inadequate attention on the underlying reasons of failure to undertake most reviews (Chin, et al., 2015). In as much as the deployment of lessons learned has been widely

Corresponding author. Email: benedictamade @ futo.edu.ng

ISSN 2560-4961 (online)

(C) 2019 IPMA Serbia

doi: 10.18485/epmj.2019.9.2.2 
publicized in project management articles and other management related fields, and given the fragmented nature of construction projects and other constraining factors, lessons learned have failed to achieve their maximum potential (Chin, et al., 2015). According to Ekambaram and Økland (2019:238); "There is an increasing focus on leveraging learning and reusing knowledge across projects". As stated by Ferrada, Núñez, Neyem, Serpell and Sepúlve (2016), most construction firms are project based organizations that are characterized by uncertainty, uniqueness and complexity, which make them unique from other business firms. With this in mind, it is cumbersome to manage the knowledge emanating from their activities via delivering of a custom-built facility. Ferrada et al. (2016) further reiterated that a lot of the project based firms are continuously failing to learn from their previous experiences, as depicted by their continued intention to 'reinventing the wheels', consistently making mistakes and failing to transfer lessons learnt from one project to the other (Desouza, \& Evaristo, 2006; Landaeta, 2008). While McClory, Read, and Labib (2017) were of the view that in as much as lessons are often identified, their capture and categorization processes are often marred with problems of both availability of time and processes, while their deployment in future projects appears to be limited to a greater extent.

The aim of the study is to identify and evaluate the constraints to lessons learned application in the successful delivery of construction projects in Nigeria. The study will be of outmost importance to project managers, professionals from the built environment and the general public knowing fully well that the lessons learned from previous projects are useful. The outcome of the study will further provide hints on how best issues bordering on lessons learned and its adoption in the delivery of construction projects could be handled with a view to ensuring the successful delivery of construction projects to schedule, cost, quality and stakeholder's satisfaction.

\section{LITERATURE REVIEW}

Lessons learned as opined by Chin et al. (2015); Ononuju, Amade, Amaeshi, Adu, and Iringe-koko (2019), is also called post project reviews, is fundamentally a method of drawing lessons from projects. While Jugdev (2012) reiterated that lessons learned is commonly used synonymously with project assessments, project reviews, project completion audits, post mortems, reviews, appraisals, after-action reviews, debriefings and post-implementation evaluations. It is broadly defined as a systematic method of capturing knowledge that accrued from a project with the sole objective of using it for the benefit of subsequent projects, most especially the future ones and for the good of the entire organization. While McClory et al. (2017) reiterated that lessonslearned process is meant to retrieve the outcomes and experiences of previous successes, failures, and other near-miss situations, and absorb them in to an organization's database with a view to using them for future use. Lessons learned according to Wiewiora, Trigunarsyah, Murphy and Chen (2009), have been validated by a project team and as such it represents the views of a consensus on the key issues that should be taken into cognizance in future projects. They further opined that lessons learned are part of the knowledge transferred that can be regulated, including transfer of mainly explicit knowledge. Jugdev (2012) defined lessons learned more broadly as learning (in its various forms) that occurs throughout the life of a project and between several projects. The main purpose of lessons learned according to Carrillo (2005), is to capture certain experiences either successful or otherwise by avoiding the repetition of mistakes that are expensive with a view to improving future performance of an organization and its stakeholders.

The United State (U.S.) Department of Energy (2008:2) defined lessons learned as a work practice or innovative approach to project management that is captured and shared to promote repeat application or an adverse work 
practice or experience that is captured and shared to prevent recurrence. In the present day project management thought, Anbari, Carayannis and Voetsch (2008), opined that there has been a long-standing belief that postproject reviews are of value. They reiterate that there is need for project evaluation to be implemented at various phases of a project's life cycle. In the termination phase of a project, a post-project evaluation ought to be carried out specifically to ascertain the level of success of the project viz a viz its planned and actual objectives. This evaluation process according to Anbari et al. (2008), should be able to explain some major variances, lessons learned from the project as well as make recommendations for the success of future projects. Albano, Kane and Thomas (2011:1) stated that the successful project manager prides his or herself on having a record of finishing on schedule, under budget, and meeting other requirements. Hence, when faced with some unexpected impediments, the need to resolve such an impediment with the outmost zeal is eminent. The project manager should as a matter of necessity and urgency deploy the lessons learned activity prior to and at the end of the project.

\subsection{Construction projects and lessons learned practices}

According to Olapade and Anthony (2012), a lot of studies have shown that a good number of building projects initiated with good intentions are abandoned at different stages of their design and construction processes. Some of the reasons responsible for the failures and subsequent abandonment were adjudged to have resulted from incorrect estimates; lack of available skilled personnel; inadequate planning; poor risk management; misunderstanding of the work requirement; poor quality control by regulatory agencies; corruption and communication gap among the personnel. Other factors are cost; the developer and the contractors; inability of clients to engage contractors or designers capability to do the work; failure on the part of contractors to obtain vital inputs such as materials, manpower and machines. Inconsistent 16 government policies, lack of accountability, high level of corruption, incompetent contractors, non -availability of building materials, lack of utilities or infrastructural facilities, wrong location and so on has been advanced as remote causes of abandonment of building project by (Olapade, \& Anthony, 2012; Ononuju, et al., 2019).

The construction industry as stated by Ferrada et al. (2016), is a knowledge-based industry. The industry relies heavily on knowledge input from the various professionals on its project's team. In as much as construction is a projectbased industry, most of its knowledge is generated from projects. The ability to capture, share, and utilize the combined knowledge of the recent workforce is critical to avoid losing essential corporate knowledge assets. This in a nutshell implies that construction firms need to dwell more on what is learned in each project with a view to continuously improve on organizational performance.

\subsection{Constraints to lessons learned application in construction projects}

A comprehensive literature review of the constraints to lessons learned is as discussed below. Although most of the constraints are components of project management, they are not a holistic representation of the entire constraints within the Nigerian environment owing largely due to paucity of researches in this area. In a multi-sector study consisting of construction, arts, healthcare and education, Paranagamage, Carrillo and Ruikar (2012) identified factors that affect project learning and knowledge transfer. The factors include; strength of the relation between two or more organizational actors, shared interpretations between parties, history of previous working relationship, absorptive capacity and motivation. Others include lack of incentives, lack of a learning culture amongst others.

In an attempt to implement lessons learned practices and indeed other knowledge management initiatives, a number of challenges have been identified as constraints 
to the implementation of lessons learned as opined by (Paranagamage, et al., 2012). The constraints include; poor organizational culture, lack of top management support, lack of dedicated resources such as staff, time and money, and poor ICT infrastructure. The processes for capturing lessons learned continues to evolve, but there are still a lot of barriers affecting lessons learned that have been identified by researchers. Notable amongst them are those identified by Larson and Gray (2011), they include; lack of time, most lessons learned are captured when the project is complete; teams get little direction or support after the lessons are reported, lessons learned often degenerate into blame sessions that becomes emotionally damaging, lessons learned are not being used across different locations, lessons learned while implementing the project are seldom used to improve the remaining work in the project. Others include too often the lessons learned are not used in future projects because the organizational culture fails to recognize the value of learning. What is needed to overcome these barriers is a methodology and management philosophy to ensure lessons learned are identified, utilized, and become a significant part of project management organizational culture (Larson, \& Gray, 2011).

While Ferrada et al. (2016), on the other hand were of the view that lessons learned databases are not widely used because the documents that exist tend to focus very much on what had been achieved by a project team only. Wiewiora et al. (2009) on the other hand identified constraints related to social communication to include; lack of social communication between projects, sharing of "bad news" is not encouraged, lack of time for social communication, lack of willingness to share project faults caused by individual or group performance. Wiewiora et al. (2009) further stated that constraints related to interproject transfer of documented lessons learned includes; lack of comprehensive approach to lessons learned including processes of transfer of lessons learned beyond the project, transfer of lessons learned is fragmented, lessons learned are not included in the project scope and/or budget, lack of a lessons learned repository, lack of time to produce lessons learned reports.

Constraints related to project manager includes; lessons learned have a low priority for the project manager, young project managers are overconfident and are reluctant to take advice from others, project managers do not like passing on their expertise and prefer to control the information (the knowledge) they possess, project managers do not want to criticize processes or people from the organization (Wiewiora, et al., 2009). Marlin (2008) articulated the following as constraints to lessons learned. They include; the lack of leadership involvement in and commitment to the learning process, separating the "accountability" issue from the "process" issue, lessons learned captured on a project seldom benefit that project, lessons learned should be captured during or at the end of each project stage, too many problems, the root cause of the problem is not always apparent, lessons learned process must ensure that the most significant lessons are institutionalized. There is need to make sure these "positive" learning's gets into the lessons learned database. For instance, are you opening yourself up for any legal action? Periodically, management should as a matter of necessity review their organization's lessons learned processes, lessons learned should be captured and placed in a database that is readily available to everyone in the organization to access easily.

\section{METHODOLOGY}

This study adopted a descriptive survey research design largely because of its inability to modify most situations under investigation. It normally involves the acquisition of information about a certain aspect of the population and getting information on their characteristics, opinions or attitudes (Kothari, 2004). The descriptive research design is appropriate where the study seeks to describe the characteristics of certain groups, estimate 
the proportion of people who have certain characteristics and make predictions. It was also useful in summarizing the data collected in a way that provided descriptive information. A snow-balling sampling method was deployed with a view to eliciting responses from the population. A total of one hundred and eleven (111) questionnaires were retrieved and from an envisaged population of about two hundred (200) which thus formed the sample size based on the snow-balling sampling technique. The snow-balling sampling technique according to Saunders, Lewis and Thornhill (2007) was adopted for this study largely due to its ability to identify difficult members from a distinct population. The main parties in the study consist of builders, architects, engineers, project managers and quantity surveyors. This response rate was necessitated by the difficulties associated with retrieving questionnaires from respondents in the study area and as such the response rate was quite commendable. Finally, one hundred and two (102) questionnaires were found useable for subsequent analyses. The use of structured questionnaires was deployed as a means of eliciting information from the practitioners. The questionnaire was designed on the basis of the information gotten from the literature review as well as personal observations of the construction projects visited in course of carrying out this study. The questionnaire was categorized into various sections. The first section deals with soliciting information about the demographic characteristics of the respondents, where it seeks to acquire information such as their primary roles and responsibilities on the construction projects in relation to lessons learned, their level of experience in the construction industry and the number of projects they have been involved in the past years. The second section sought to look at the constraints to lessons learned activities in the delivery of construction projects. The questionnaires comprises of close-ended and a few open-ended questions that were fussed with a view to getting details from the practitioners as well as clearer picture on some of the issues in context. The questionnaire was formulated using A Likert five point scale 18 ranging from 1-5 intervals. Semi-structured Interviews were also utilized with a view to identifying other underlying issues bordering on lessons learned and its application in the construction process. While performance data on some previous construction projects data bordering on lesson learned activities were also consulted and utilized for purpose of this study from some selected ongoing construction projects located in Port-Harcourt in Rivers State. The survey instruments were further subjected to face, content and construct validly test via previous researches done in the past. According to Somekh and Lewin (2004), validity is the extent to which a researcher has measured what he or she sets out to measure. Thus it is the state of accuracy or meaningfulness of interferences that is associated with research outputs. Validity is the degree to which an instrument achieves and measuring what it is expected to measure. While reliability as stated by Somekh and Lewin (2004), is the tendency of a questionnaire to consistently and continuously give similar results under the same conditions. Reliability test was conducted using Cronbach's alpha coefficient test. In a bid to achieve the objectives of this study, the use of both primary and secondary methods of data collections was deployed. The questionnaires were designed based on the information needed, as well as who needs the information, method of communication to be adopted viz (email, telephone or personal interview). The researcher had semi-structured interviews with some key professionals from the construction firms/projects visited. The primary data collection method was adopted largely due to its ability to provide first hand information, as well as confirm some issues raised in some of the data collected via the questionnaire and captured some other details about lessons learned that might have been left out in the questionnaires.

The collected data were organized for analysis by carrying out data cleaning which involved editing, coding, tabulating. Descriptive statistics was deployed in analyzing the quantitative data. While charts and figures were used to present and explain the results. 
Factor analytical technique (factor analysis) was adopted in evaluating the barriers to lessons learned application in the delivery of construction projects in the study area. This was achieved with the aid of IBM SPSS version 20 . In analyzing the data collected, the weighted score of respondents to each of the barriers (factors) to lessons learned were generated. The factor analysis technique is a method of quantitative multivariate analysis that aids in representing the interrelationships that exists among a set of continuously measured variables that are usually represented by their interrelationships usually an underlying linearly independent reference variables known as factors. The method further seeks to collapse a set of numerous operating variables into a selected fewer interrelated attributes called principal components (Gaur and Gaur, 2009). The eigenvalue determines the principal components that are orthogonally varimax rotated with a view to obtaining more evenly distributed variables amongst a set of components. Factor analysis assumes a mathematical procedure that an $\mathrm{n} \times \mathrm{n}$ matrix A has an eigenvalue $\lambda$, if there exists a non-zero vector $\mathrm{x}$, called an eigenvector associated with $\lambda$, for which (Pallant, 2005):

$\mathrm{Ax}=\lambda \mathrm{X}$

Thus the model shows that the matrix $A-\lambda I$ is singular and therefore;

$\operatorname{det} ;(\mathrm{A}-\lambda \mathrm{I})=0$.

Table 1: Cronbach's alpha coefficient

\begin{tabular}{|c|c|}
\hline \multicolumn{2}{|c|}{ Reliability Statistics } \\
\hline Cronbach's Alpha & N of Items \\
\hline .894 & 15 \\
\hline
\end{tabular}

The result of the Cronbach's Alpha coefficient of all the fifteen (15) constraints to lessons learned application for successful construction project delivery is 0.894 . This is a clear indication that the instrument is reliable. In a nutshell, the instrument deployed for this study was adjudged reliable given the results of the reliability statistics shown in table 1 .

\subsubsection{Demographic information}

Section one of the questionnaire captured the respondent's characteristics in viz; their

\subsection{Results and discussions}

\subsubsection{Questionnaire response}

The study population consists of 200 practitioners from some selected construction firms located in Port-Harcourt, Rivers State. The snow balling sampling technique was used in selecting the professionals from the construction firms. Thereafter 111 questionnaires were retrieved which later formed the sample size based on the snowballing technique, while 102 questionnaires were later found to be fit for further data analyses.

\subsubsection{Reliability tests}

The consistency level for each item in the category related to the questions bordering on the barriers to lessons learned application for successful construction project delivery was conducted using the Cronbach's alpha. The Cronbach's alpha coefficient as opined by Pallant (2005) has been adjudged as a critical tool for determining the extent of reliability of a data. The table below shows the result of the internal consistency of the various categories of item of the constraints to lessons learned using IBM SPSS version 20.

discipline, years of experience in the industry, qualifications as well as types of project executed, constraints to lessons learned etc.

\subsubsection{Respondents discipline}

Figure 1 shows the respondents discipline, 28 $(27.45 \%)$ are engineers, $18(17.65 \%)$ are quantity surveyors, $10(9.80 \%)$ are architects, $15(14.71 \%)$ are project managers, 13 $(12.75 \%)$ builders, while others are 18 $(17.65 \%)$. 


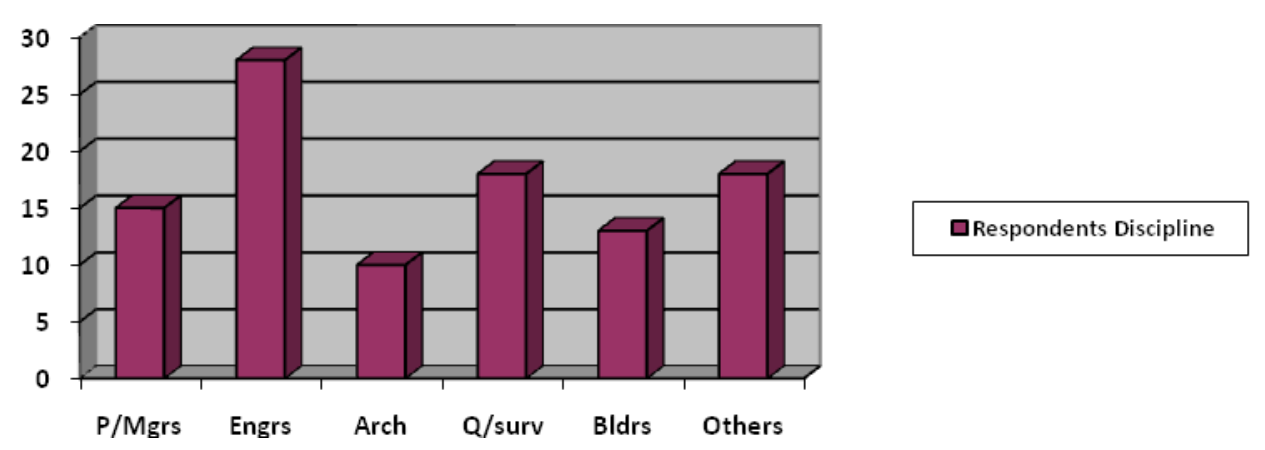

Figure 1: Respondents discipline

\subsubsection{Respondents years of experience in the industry}

Figure 2 depicts the experience of the respondents in the industry. $16(15.69 \%)$ of the spent between 6-10 years, 48 (47.06\%) $11-15$ respondents have spent 1-5years, 18 (17.65\%) years, $12(11.76 \%)$ 16-20 years, while 8 $(7.84 \%)$ spent over 21 years in the industry.

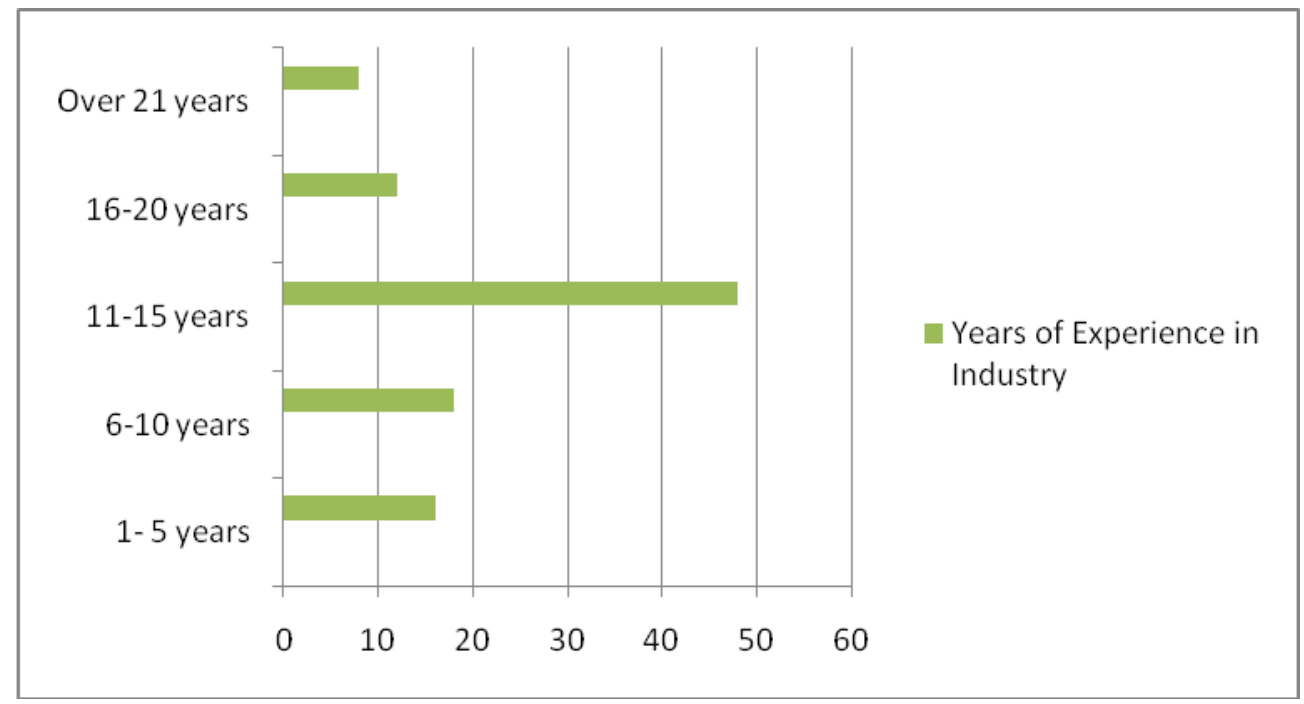

Figure 2: Respondents years of experience in the industry

\subsubsection{Respondents academic qualification}

Figure 3 shows the academic qualifications possessed by the respondents. In all 17 $(16.67 \%)$ had OND (ordinary national diploma) as qualification, $62(60.78 \%)$ had HND (higher national diploma) /B.Sc/B.Eng, $23(22.55 \%)$ had MBA/M.Sc as qualification, while none had

Ph.D. 


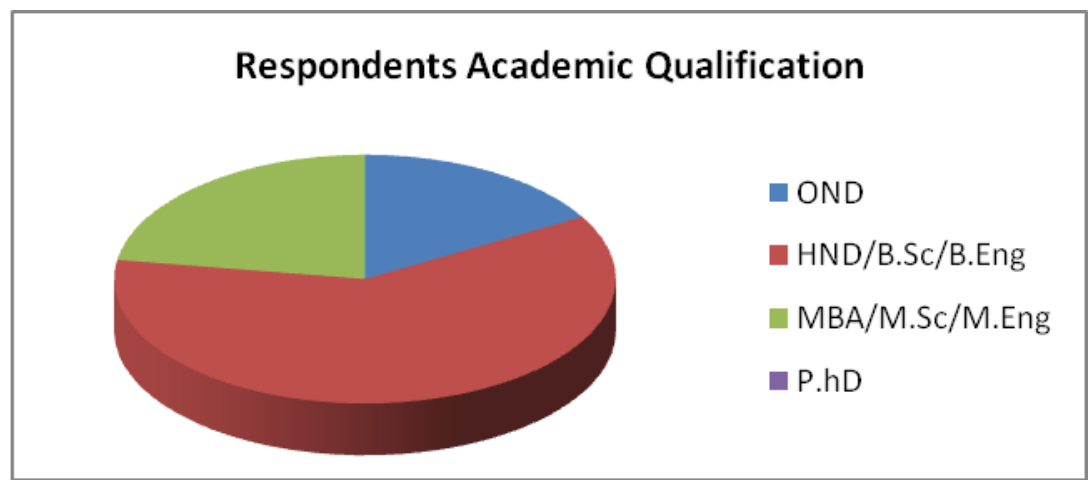

Figure 3: Respondents academic qualification

\subsubsection{Types of construction projects that $25(24.51 \%)$ were building projects, 52} executed

$(50.98 \%)$ are road projects, $12(11.76 \%)$ were On the types of construction projects executed bridges, while others were $13(12.75 \%)$. by the respondents, the figure below shows

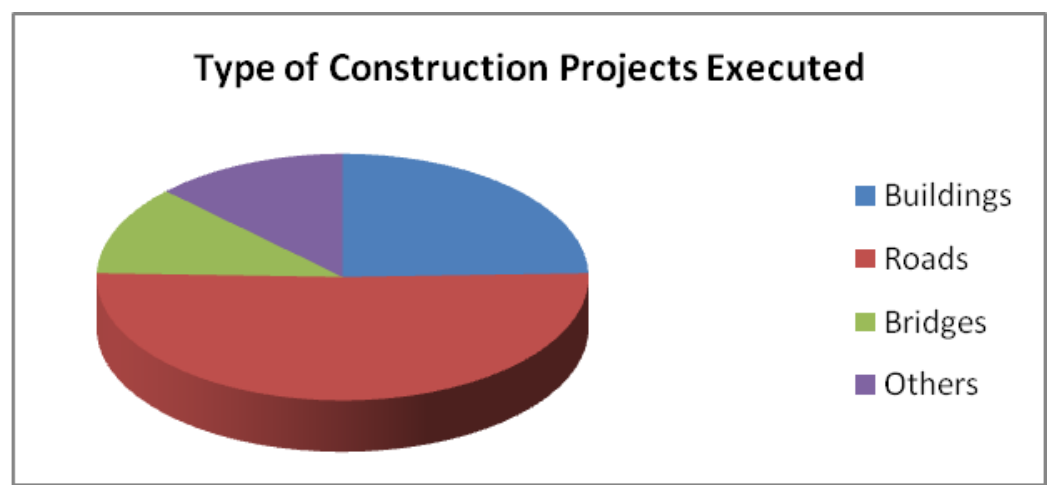

Figure 4: Specific types of construction projects executed

3.1.9 Constraints to lessons learned application to construction project deliverySurvey findings

The respondents were made to indicate their level of agreement with the identified constraints to lessons learned application to successful construction project delivery based on their experience in their organizations. The findings are presented in Tables 2. Fifteen (15) factors were identified from the literature as constraints to lesson learned application to successful construction project delivery. The (15) factors are shown in table 2.

Table 2: Constraints to lessons learned application to construction projects

\begin{tabular}{|l|l|c|}
\hline & Constraints to lessons learned application & Symbol \\
\hline 1 & Lack of time & $\mathrm{X}_{1}$ \\
\hline 2 & Teams get little direction or support after the lessons are reported & $\mathrm{X}_{2}$ \\
\hline 3 & Degeneration into blame sessions that becomes emotionally damaging & $\mathrm{X}_{3}$ \\
\hline 4 & Lesson learned not being used across different locations & $\mathrm{X}_{4}$ \\
\hline 5 & Lesson learned is seldom used to improve the remaining work in the project & $\mathrm{X}_{5}$ \\
\hline 6 & Lesson learned is not used in future projects because the organizational & $\mathrm{X}_{6}$ \\
\hline
\end{tabular}




\begin{tabular}{|l|l|c|}
\hline & culture fails to recognize the value of learning & \\
\hline 7 & Poor organizational culture & $\mathrm{X}_{7}$ \\
\hline 8 & Lack of top management support & $\mathrm{X}_{8}$ \\
\hline 9 & $\begin{array}{l}\text { Lack of dedicated resources such as staff, time and money, and poor ICT } \\
\text { infrastructure }\end{array}$ & $\mathrm{X}_{9}$ \\
\hline 10 & Lack of a lessons learned repository & $\mathrm{X}_{10}$ \\
\hline 11 & Lack of comprehensive approach to lessons learned & $\mathrm{X}_{11}$ \\
\hline 12 & Lessons learned are not included in the project scope and/or budget & $\mathrm{X}_{12}$ \\
\hline 13 & $\begin{array}{l}\text { Lack of willingness to share project faults caused by individual or group } \\
\text { performance }\end{array}$ & $\mathrm{X}_{13}$ \\
\hline 14 & Lack of social communication between projects & $\mathrm{X}_{14}$ \\
\hline 15 & Lack of time to produce lessons learned reports & $\mathrm{X}_{15}$ \\
\hline
\end{tabular}

The results of the analysis using factor analysis are as shown from tables 3 to 4 respectfully.

Table 3: KMO and Bartlett's test for constraints to lessons learned application for construction projects.

\begin{tabular}{|l|l|r|}
\hline \multicolumn{2}{|c|}{ KMO and Bartlett's Test } \\
\hline Kaiser-Meyer-Olkin Measure of Sampling Adequacy. & .598 \\
\hline \multirow{3}{*}{ Bartlett's Test of Sphericity } & Approx. Chi-Square & 561.173 \\
\cline { 2 - 3 } & Df & 105 \\
\cline { 2 - 3 } & Sig. & .000 \\
\hline
\end{tabular}

The following tests were required to test for the appropriateness of factor analysis for factor extraction, including the Kaiser-Meyer-Olkin (KMO) measure of sampling accuracy, antiimage correlation, measure of sampling activities (MSA) and Barlett test of sphericity. The outcomes of these tests are displayed in table 3 . The 15 factors were subjected to factor analysis, with principal component analysis and varimax rotation. In the first instance, the analysis is to determine the strength of the relationship between the variables based either on correlation coefficients or partial correlation coefficients of the variables. The Barlett's test of sphericity is assumed to tests the hypothesis that the correlation matrix is an identity matrix. In this case, the value of the test statistic for sphericity was large (Barlett test of sphericity=561.173) and the associated significance level is small $(\mathrm{p}=0.000)$, suggesting that the population correlation matrix is not an identity matrix. An observation of the correlation matrix of the barriers to lessons learned application for successful construction project delivery shows that they all have significant correlation at 5\% level, depicting that there would be no need to eliminate any of the variables from the principal component analysis.

The value of the KMO statistic is 0.598 which is not less than 0.6 which according to Gaur and Gaur (2009), is a satisfactory condition for factor analysis to hold. Hence, these tests indicate that factor analysis is the appropriate tool for factor extraction and as such factor analysis was adopted for the study. 
Table 4: Communalities, total variance explained and component matrix for constraints to lessons learned for construction projects.

\begin{tabular}{|c|c|c|c|c|c|c|c|c|}
\hline \multicolumn{7}{|c|}{ Component Matrix } \\
\hline $\mathrm{X}_{11}$ & .845 & .756 & & & & & \\
\hline $\mathrm{X}_{2}$ & .771 & .739 & & & & & & \\
\hline & Communalities & 1 & 2 & 3 & 4 & 5 & 6 & \\
\hline $\mathrm{X}_{14}$ & .736 & .712 & & & & & & \\
\hline $\mathrm{X}_{8}$ & .825 & .690 & & & & & & \\
\hline $\mathrm{X}_{12}$ & .853 & .686 & & & & & & \\
\hline $\mathrm{X}_{4}$ & .662 & .614 & & & & & & \\
\hline $\mathrm{X}_{9}$ & .787 & .593 & & & & & & \\
\hline $\mathrm{X}_{1}$ & .780 & & .738 & & & & & \\
\hline $\mathrm{X}_{15}$ & .807 & & .575 & & & & & \\
\hline $\mathrm{X}_{3}$ & .812 & & & .598 & & & & \\
\hline $\mathrm{X}_{6}$ & .872 & & & & & & & \\
\hline $\mathrm{X}_{7}$ & .811 & & & & .677 & & & \\
\hline $\mathrm{X}_{5}$ & .792 & & & & .614 & .512 & & \\
\hline $\mathrm{X}_{13}$ & .898 & & & & & & .726 & \\
\hline $\mathrm{X}_{10}$ & .799 & & & & & & & .580 \\
\hline $\begin{array}{l}\text { \% of } \\
\text { Variance }\end{array}$ & & & & & & & \\
\hline $\begin{array}{l}\text { Cumulative } \\
\text { \% }\end{array}$ & & & & & & & & \\
\hline $\begin{array}{l}\text { Extraction Method: Principal Component Analysis. } \\
\text { a. 7 components extracted. }\end{array}$ & & & & & & & \\
\hline
\end{tabular}

In estimating the possible intensity of the constraints to lessons learned application for successful construction project delivery was achieved with the aid of the communality extraction as depicted in table 4. The least extraction value of 0.662 is associated with the factor $\mathrm{X}_{4}$, lessons learned not being used across different locations, while the highest extraction value of 0.898 is associated with the factor $\mathrm{X}_{13}$, lack of willingness to share project faults caused by individual or group performance. This shows that each of the factors has indicated some potentials for affecting the barriers to lessons learned application for successful construction project delivery.

A total of seven (7) principal components were extracted from the initial fifteen (15) constraints. These seven components generated cumulative variance explanation of $80.346 \%$ as shown by the extracted sums of square loading in table 4 . When the above varimax is rotated, it generated the same sums of squares loading also. The findings from the results shown above indicates that 15 -factors can be grouped into seven decision matrix (components) for constraints to lessons learned application for successful construction project delivery. However, 6-principal components were later extracted for effectiveness. In the first component, 7 factors $\left(X_{11}, X_{2}, X_{14}, X_{8}\right.$, $\mathrm{X}_{12}, \mathrm{X}_{4}$, and $\mathrm{X}_{9}$ ) in that order loads positively maximally, 2 factors $\left(\mathrm{X}_{1}\right.$ and $\left.\mathrm{X}_{15}\right)$, loads positively maximally in the second component, while 1 factor $\left(\mathrm{X}_{3}\right)$ loads positively maximally in the third component. In the fourth component, 2 factors $\left(\mathrm{X}_{7}\right.$ and $\left.\mathrm{X}_{5}\right)$ load positively maximally. In the fifth component, no factor loaded. In the sixth component, 1 factor $\left(\mathrm{X}_{13}\right)$ loaded positively maximally. 
While finally in the seventh component, 1 factor $\left(\mathrm{X}_{10}\right)$ loaded positively maximally.

\subsection{Discussion of results}

On the constraints to lessons learned application, the study found that although the fifteen (15) factors were identified from the literature as constraints to lessons learned application to successful construction project delivery. The practitioners understood these factors in seven key dimensions (factors 1-7) as presented in table 4. A further examination of the constraints to lessons learned application gave rise to 6-principal components which were later extracted for effectiveness. In the first component, lack of comprehensive approach to lessons learned loaded positively maximally, in the second component, lack of time loads positively maximally, in the third component, degeneration into blame sessions that becomes emotionally damaging loaded positively maximally. In the fourth component, poor organizational culture load positively maximally. In the fifth component, lack of willingness to share project faults caused by individual or group performance loaded positively maximally. While in the sixth component, lack of a lessons learned repository loaded positively and maximally. These findings are also in line with those existing in the literature to a greater extent most importantly that of (Larson, \& Gray, 2011; Paranagamage, et al., 2012, Wiewiora, et al., 2009) who were of the view that constraints to lessons learned are mostly related to inter-project transfer of documented lessons learned evidences which includes processes of transfer of lessons learned beyond the project amongst others.

\section{CONCLUSION AND RECOMMENDATIONS}

From the outcomes of the results, the study now concludes that; The most significant constraints to the deployment /application of lessons learned in the delivery of construction projects are; lack of comprehensive approach to lessons learned; lack of time; degeneration into blame sessions that becomes emotionally damaging; poor organizational culture; lack of willingness to share project faults caused by individual or group performance; and lack of a lessons learned repository. On the constraints to lessons learned adoption/application in construction project delivery, this study recommends that a comprehensive approach to lessons learned forum be created through conferences, workshops, face-to-face interactions with a view to help understanding what lessons learned is all about. In the absence of a concerted effort of this sort in place, the tendency to get the lessons learned technique to the delivery of construction projects in Nigeria would not be achieved. Further work is required in the areas of lessons learned associated with larger infrastructure projects that are not just limited to the core areas of construction, but to include other aspects of both IT, industrial based and other mega development projects.

\section{REFERENCES}

Albano, M., Kane, B., \& Thomas, R. (2011). Project management best practices. Improving scheduling using a distributed workforce. The Official Magazine of ISPE, 31(5), 1-4.

Anbari, F. T., Carayannis, E. G., \& Voetsch, R. J. (2008). Post-project reviews as a key project management competence. Technovation, 28, 633-643.

Carrillo, P. M. (2005). Lessons learned practices in the engineering, procurement and construction sector. Engineering, Construction and Architectural Management, 12(3), 236-250.

Che Munaaim, M. E., Abdul-Rahman, H., Low, W. W., \& Yahya, I. A. (2007). Developing competent Malaysian contractors through the use of project learning approach-The case of Malaysia. Proceedings of the Built Environment Education Conference, (CEBE) 2007 (pp1-11).

Chin, B. W. A., Gao, S., \& Low, S. P. (2015). An institutional approach to understanding post-project reviews in the construction industry. International Surveying Research Journal, 5(1), 1-19. 
Desouza, K. C. \& Evaristo, R. J. (2006). Project management offices: A case of knowledge - based archetypes. International Journal of Information Management, 26(5): 414-423.

Duffield, S., \& Whitty, J. (2012). A systemic lessons learned and captured knowledge (SLLCK) model for project organizations. In: Proceedings of the Annual Project Management Australia Conference Incorporating the PMI Australia National Conference (PMOz) Aug 15-16, 2012 (pp1-11), Melbourne, Australia.

Ekambaram, A., \& Økland, A. (2019). Ensuring successful knowledge transfer in building renovation projects. Emerald Reach Proceeding Series, 2, 237-242.

Ferrada, X., Núñez, D., Neyem, A., Serpell, A., \& Sepúlve, M. (2016). A cloud-based mobile system to manage lessons-learned in construction projects. Procedia Engineering, 164, 135-142.

Gaur, A. S., \& Gaur, S. S. (2009). Statistical methods for practice and research: a guide to data analysis using SPSS. $\left(2^{\text {nd }}\right.$ ed.). New Delhi, India: SAGE Publications Inc.

Jugdev, K. (2012). Learning from lessons learned: Project management research program. American Journal of Economics and Business Administration, 4(1), 13-22.

Kothari, C. K. (2004). Research methodology: methods and techniques. ( $2^{\text {nd }}$ revised ed.). New Delhi, India: New Age International Publishers.

Landaeta, R. E. (2008). Evaluating benefits and challenges of knowledge transfer across projects. Engineering Management Journal, 20(1): 29-39.

Larson, E. W., \& Gray, C. F. (2011). Project management: the managerial process. $\left(5^{\text {th }}\right.$ ed.): McGraw-Hill/Irwin.

Marlin, M. (2008). Implementing an effective lessons learned process in a global project environment. Proceedings of the UTD 2nd Annual Project Management Symposium, 2008 (pp1-6), Dallas, Texas.

McClory, S., Read, M., \& Labib, A. (2017). Conceptualizing the lessons-learned process in project management: Towards a triple-loop learning framework. International Journal of Project Management, http://dx.doi.org/10.1016/j.ijproman.2017. 05.006

Olapade, O., \& Anthony, O. (2012). Abandonment of building projects in Nigeria- a review of causes and solutions. International Conference on Chemical, Civil and Environmental Engineering (ICCEE2012) March, 24 - 25 (pp 253255) Dubai.

Ononuju, C. N., Amade, B., Amaeshi, U. F., Adu, E. T., \& Iringe-koko, P. K. (2019). Extent of the application of lessons learned in construction projects: The Nigerian experience. International Academic Journal of Information Sciences and Project Management, 3(3), 45-58.

Pallant, J. (2005). SPSS survival manual: $a$ step by step guide to data analysis using SPSS for windows (version 12). Crows Nest, Australia: Allen \& Unwin.

Paranagamage, P., Carrillo, P. M., \& Ruikar, K. D. (2012). Lessons learned practices in the UK construction sector: current practice and proposed improvements. Engineering Project Organization Journal, 2(4), 216-230.

Saunders, M., Lewis, P., \& Thornhill, A. (2007). Research methods for business students. $\quad 4^{\text {th }}$ ed.). England: Pearson Education Limited.

Somekh, B., \& Lewin, C. (2004). Research methods in the social sciences. London: SAGE Publications Inc.

U.S. Department of Energy (2008). Project management lessons learned initiated by office of engineering and construction management Washington, D. C. Retrieved from http://www.directives.doe.gov on $12^{\text {th }}$ May, 2016.

Wiewiora, A., Trigunarsyah, B., Murphy, G., \& Chen, L. (2009). Barriers to effective knowledge transfer in project-based organizations. In: Proceedings of the 2009 International Conference on Global Innovation in Construction Proceedings Sept 13-16, 2009, Holywell Park, Loughborough University. 